\title{
Some New Trends in Multiobjective Programming Problems Under Uncertainty
}

MK Luhandjula*

Department of Decision Sciences, University of South Africa, PO Box 392, UNISA; Pretoria 0003, South Africa

\begin{abstract}
In this postmodernism era characterized by the fragmentation of the truth, the ascendency of subjective perceptions and the triumph of approximative reasoning it is crucial to take into account imprecision and uncertainty in scientific models. In this Editorial, we indicate some new trends in ways for dealing with Multi objective Programming Problems (MOPP) under uncertainty.
\end{abstract}

\section{Introduction}

Many non trivial real life decision problems are hardly modeled in deterministic terms because of uncertainty or incompleteness of related information.

In this connection the British Economist Shackle [1] was saying: "In a predestinate world, decision would be illusory; in a world of prefect foreknowledge, empty; in a world without order, powerless. Our intuitive attitude to life implies non-illusory, non-empty, nonowerless decision ... Since decision in this sense excludes both perfect foresight and anarchy in nature, it must be defined as choice in face of bounded uncertainty". This has also been well expressed by Zadeh's incompatibility principle [2]. "When the complexity of a system increases our ability to formulate precise and yet meaningful statements decreases up to a threshold beyond which precision and significance become mutually exclusive characteristics."

In this Editorial, we outline some new trends in ways for dealing with Multi objective Programming Problems under uncertainty.

\section{Stochastic Multiobjective Programming Problems}

Uncertainty can be described in several ways, depending on the information at hand. Among mathematical tools for coping with uncertainty we mention worst case scenario analysis, evidence theory, probability theory and fuzzy set theory.

As Probability theory is the most well grounded of these tools, it is not a surprise that Stochastic Multiobjective Programming (SMP) is the most developed topic on multiobjective programming under uncertainty.

A look at the literature reveals that most existing approaches for solving (SMP) problems rely heavily on the expected, pessimistic and optimistic values of involved random variables $[3,4]$.

Findings from several research works [5] leave no doubt about the fact that these values may be useful in providing the range of possible outcomes. Nevertheless, they ignore such important factors as the size and the probability of deviation outside the likely range as well as other aspects concerning the dispersions of involved probabilities.

A New trend in this field is that of singling out satisfying solutions based on the chance-constrained paradigm [6]. Approaches along this trend add considerably to both the flexibility and the effectiveness of a Multi objective Stochastic Program.

\section{Fuzzy Multiobjective Programming Problems}

The past three decades have witnessed a huge interest in Fuzzy multi objective programming problems $[7,8]$. Nevertheless existing approaches for solving multi objective programming problems with fuzzy objective functions are either effective [9] or computationally efficient [10] but not both.

The new trend in this field is to strike a balance between the faithful translation of the original fuzzy problem into deterministic terms and the computational attractiveness of the resulting deterministic program [11].

This is done either by the choice of an optimal deffuzification approach or by an Embedding Theorem for fuzzy numbers.

\section{Fuzzy Stochastic Multiobjective Programming Problems}

New trends for the multiobjective programming problems under uncertainty outlined in sections 2 and 3 have been canonically extended to situations where randomness and fuzziness co-occurs in a multi objective setting [12].

\section{Concluding Remarks}

We have pointed out new trends in the field of Multi objective Programming problems under uncertainty.

Case studies should be carried out, in a way to make transition from theory to practice in this field.

\section{References}

1. Shackle GLS (1961) Decision, Order and Time in Human Affairs. Cambridge University Press.

2. Dubois D, Prade H (1980) Fuzzy sets and systems. Academic Press.

3. Caballero R, Cerda E, Munoz MM, Rey L (2000) Relations among severa efficient concepts in Stochoastic Multiobjective Programming. Research and Practice in Multiple Criteria Decision Making 487:57-68.

4. Caballero R, Cerda E, Munoz MM, Rey L, Stancu IM (2001) Minasian Efficient

*Corresponding author: Professor, Department of Decision Sciences, University of South Africa, PO Box 392, UNISA; Pretoria 0003, South Africa, E mail: Luhanmk@unisa.ac.za

Received July 25, 2013; Accepted July 27, 2013; Published August 02, 2013

Citation: Luhandjula MK (2013) Some New Trends in Multiobjective Programming Problems Under Uncertainty. Ind Eng Manage 2: e116. doi: 10.4172/21690316.1000e116

Copyright: $\odot 2013$ Luhandjula MK. This is an open-access article distributed under the terms of the Creative Commons Attribution License, which permits unrestricted use, distribution, and reproduction in any medium, provided the original author and source are credited. 
Citation: Luhandjula MK (2013) Some New Trends in Multiobjective Programming Problems Under Uncertainty. Ind Eng Manage 2: e116. doi: 10.4172/2169-0316.1000e116

Page 2 of 2

solution concepts and their relations in Stochastic Multiobjective Programming. J Optim Theory and Appl 110: 53-74.

5. Adeyefa AS, Luhandjula MK (2011) Multiobjective Stochastic Linear Programming: An Overview. American J Oper Res 1: 203-2013.

6. Charnes A, Cooper WW (1959) Chance-Constrained Programming. Manage Sci 6: 73-79.

7. Luhandjula MK (1989) Fuzzy Optimization: An appraisal. Fuzzy sets and sys 30: 257-282.

8. Cadenas JM, Verdegay JL (2000) Using ranking functions in multi objective fuzzy linear programming. Fuzzy sets and sys 111: 47-53.

9. Inuiguchi M, Sakawa M (1996) Possible and necessary efficiency in possibilistic multiobjective linear programming problems and possible efficiency test. Fuzzy sets and Sys 78: 231-241.

10. Kou G, Li B, Zheng M (2011) The expected value model of multiobjective programming and its solution method based on bifuzzy environment. JCP 6:1942-1948.

11. Luhandjula MK, Rangoaga MJ (2013) Mathematical programming problems with several fuzzy objective functions. Int $\mathrm{J}$ Uncertainty Fuzziness and Knowledge-Based Sys 21: 51-62.

12. Luhandjula MK (2012) A connection between fuzzy random variables and random closed sets with application to Fuzzy Stochastic Optimization. J Fuzzy Math 20: 335-346. 